УДК $551.5(075.8)$

\title{
КЛИМАТИЧЕСКИЕ КОЛЕБАНИЯ ТЕМПЕРАТУРЫ И ОСАДКОВ В СЕВЕРНОМ КАЗАХСТАНЕ
}

\author{
А. В. Чередниченко, А. В. Чередниченко, В. С. Чередниченко
}

НИИ проблем биологии и биотехнологии Казахского национального университета им. Аль-Фараби, Казахстан

Поступила в редакиию 7 мая 2018 г.

\begin{abstract}
Аннотация: Рассмотрены особенности климатических изменений температуры и осадков в Северном Казахстане. Было показано, что климатические изменения происходят с некоторой временной задержкой. Основой для построения сценариев является предположение, что гармоники, содержащиеся во временных рядах температуры и осадков и образующие эти ряды, являются результатом действия определенного фактора или суммы факторов. Есть основания ожидать, что действие этих факторов будет продолжаться и в будущем. В предположении сохранения основных гармоник построены сценарии ожидаемых климатических изменений температуры и осадков в регионе на период до 2040-2050 годов.

Зная особенности формирования временных рядов осадков, мы обнаружили и использовали связи между климатическими изменениями осадков и климатическими колебаниями в показателях общей циркуляции атмосферы (волны Россби), выявленных в процессе гармонического анализа.

Мы получили, что в течение следующих 40-50 лет температура в Северном Казахстане снизится до амплитуды вековой гармоники и приблизится к примерно $2^{\circ} \mathrm{C}$ в конце периода. Флуктуация температуры, обусловленная второй и третьей гармониками, не будет превышать $0,8^{\circ} \mathrm{C}$.

На период до 2050 года в Северном Казахстане наиболее вероятно, что количество осадков с незначительными колебаниями приблизилось в настоящее время к его максимуму, а в тридцатые годы XXI достигнет своего минимума. Наиболее вероятна амплитуда колебаний \pm 20 мм от нормы.
\end{abstract}

Ключевые слова: изменение климата, осадки, температура, Северный Казахстан, вероятностный и статистический метод, полином шестой степени, гармонический анализ.

\section{Climatic fluctuations in temperature and precipitation in northern Kazakhstan A. V. Cherednichenko, A. V. Cherednichenko, V.S. Cherednichenko}

Abstract: The features of climatic changes in temperature and precipitation in Northern Kazakhstan are considered. It was shown that climatic changes occur with some time delay. The basis for the construction of scenarios is the assumption that the harmonics contained in the time series of temperature and precipitation and forming these series are the result of the action of a certain factor or the sum of factors. There is reason to expect that the effect of these factors will continue in the future. Under the assumption of conservation of the main harmonics, scenarios of expected climatic changes in temperature and precipitation in the region for the period up to 2040-2050 are constructed.

Knowing the features of the formation of time series of precipitation, we found and used the relationships between climatic changes in precipitation and climatic fluctuations in the parameters of the general circulation of the atmosphere (Rossby waves) revealed in the process of harmonic analysis.

We have obtained that over the next 40 to 50 years the temperature in Northern Kazakhstan will decrease to the amplitude of the age-old harmonic and will approach about $2^{\circ} \mathrm{C}$ at the end of the period. The temperature fluctuations due to the second and third harmonics will not exceed $0.8^{\circ} \mathrm{C}$.

For the period up to 2050 in Northern Kazakhstan it is most likely that the amount of precipitation with

() Чередниченко А.В., Чередниченко А.В.,

Чередниченко В.С., 2019 
minor fluctuations has now approached its maximum, and in the thirties the XXI will reach its minimum. The amplitude of oscillations is most likely $\pm 20 \mathrm{~mm}$ from the norm.

Key words: climate change, precipitation, temperature, Northern Kazakhstan, probabilistic and statistical method, sixth-degree polynomial, harmonic analysis.

\section{ВВЕДЕНИЕ}

Северный Казахстан является основным сельскохозяйственным регионом республики, обеспечивающим его продовольственную безопасность. Естественно, что проблема изменения климата и его влияние на сельскохозяйственное производство в этом регионе чрезвычайно важны.

Территория Северного Казахстана относится к зоне рискованного сельского хозяйства, где из каждых пяти лет только три являются в среднем урожайными. Районы поливного земледелия, расположенные на юге республики, удовлетворяют только местные потребности в продовольствии. Поэтому, несмотря на проблемы, Северный Казахстан является основным сельскохозяйственным регионом.

Зоны рискованного сельского хозяйства слишком чувствительны к изменению климата из-за того, что системы окружающей среды находятся в неустойчивом балансе и незначительные, но длительные изменения количества осадков или температуры, могут привести к необратимым последствиям. Понятно, что анализ возможных климатических изменений в регионе Северного Казахстана имеет не только научный, но и практический интерес.

\section{ОБЛАСТЬ ИССЛЕДОВАНИЙ}

Территория Северного Казахстана простирается с юга на север от $51^{\circ}$ до $55,5^{\circ}$ с.ш. и с запада на восток от $61^{\circ}$ до $78^{\circ}$ в.д. Здесь расположены четыре области республики: Северо-Казахстанская (Петропавловск), Костанайская (Костанай), Целиноградская (Нур-Султан) и Павлодарская (Павлодар). Однако южные районы Костанайской и Павлодарской областей уже не имеют высокой сельскохозяйственной ценности из-за уменьшения количества осадков и повышения температуры в течение вегетационного периода.

Территория расположена в центре Евразии и характеризуется большими амплитудами годовой температуры и малым количеством осадков из-за большого расстояния от океанов, особенно от Атлантического океана.

В нашей статье использовались официальные данные гидрометеорологической службы Казахстана, а именно: среднемесячные характеристики температуры и осадков на станциях Северного Казахстана за период наблюдений с начала XX века до настоящего времени [10]. Кроме того, наши коллеги любезно предоставили нам некоторые данные о структуре сельского хозяйства в регионе.

\section{МЕТОДИКА}

Мы отказались от линейной экстраполяции температурных и временных рядов, поскольку линейные тренды обладают большой инерцией. Для перехода от положительной тенденции к отрицательной требуется до 10 лет или более. Это время необходимо для компенсации накопленной положительной суммы отклонений и достижения нейтрального тренда. Только после этого возможен переход к отрицательной тенденции. Поэтому мы аппроксимировали наши ряды полиномом шестой степени, обеспечивая значительное сглаживание ряда, в котором, однако, сохраняются климатические особенности. Такая полиномиальная аппроксимация довольно чувствительна к общей тенденции ряда и улавливает ее изменения довольно быстро, в течение нескольких лет. Недостаток такого метода аппроксимации состоит в том, что он очень чувствителен на конце ряда, и мы не знаем, как долго сохранится тенденция в изучаемом параметре. Поэтому, кроме полиномиальной аппроксимации, мы широко используем гармонический анализ временных рядов. Гармонический анализ, как мы знаем, представляет временной ряд в виде некоторой суммы тригонометрических функций, каждая из которых выбирает долю дисперсии изучаемого параметра. Чем быстрее временной ряд сходится, тем меньшим числом гармоник выбирается основная часть дисперсии. В нашем исследовании до 95 \% дисперсии во временных рядах температуры выбирают первые три гармоники, а в рядах осадков - четыре. Следовательно, временные ряды осадков сходятся медленнее, чем ряды температуры. Мы, однако, в этой статье оцениваем вклад гармоник не в долях дисперсии, а по их амплитуде. Это позволяет нам измерять вклад каждой из гармоник в градусах и миллиметрах соответственно, что очень удобно и физически наглядно.

Если аппроксимация полиномом шестой степени сглаживает временной ряд и быстро реагирует на изменение тренда в динамике ряда, то гармоники характеризуют внутреннюю структуру 
ряда. Каждая гармоника может интерпретироваться как результат влияния группы факторов. Нет оснований считать, что факторы, участвовавшие в формировании временного ряда раньше, затем исчезнут. Это дает нам возможность уточнить результаты полиномиальной аппроксимации на краю временного ряда по основным гармоникам. В то же время это позволяет нам построить сценарий изменения временной строки на 20-40 лет вперед как сумму амплитуд основных гармоник, экстраполированных на перспективу в каждой временной точке.

В настоящее время существует высокая стабильность количества поступающей солнечной энергии $[22,24,26]$. В таком случае климатические колебания в регионе объясняются только колебаниями общей циркуляции в атмосфере. Все другие параметры, формирующие климат, для конкретной точки и региона неизменны. Для описания общей циркуляции были использованы хорошо известные индексы (типы) Г. Я. Вагенгейма для первого естественного синоптического района, простирающегося от середины Атлантического океана до меридиана $100^{\circ}$ в.д. [2]. Территория Казахстана полностью входит в первый естественный синоптический район. Эта типология основана на локализации волн Россби, т. е. в основу типизации положено территориальное положение ложбин и гребней в поле геопотенциала в средней тропосфере. Если в европейской части России, то есть к западу от Урала, есть ложбина, то восточнее гор располагается гребень. Такая ситуация называется С-типом (смешанным). При обратном расположении ложбин и гребней тип называется E (East). В этой ситуации ось высокого атмосферного давления может перемещаться на восток или совпадать с осью горного хребта.

Если гребни и ложбины выражены слабо, имеют место слабые меридианные смещения при общем движении воздушных масс с запада на восток, то такой тип называется $\mathrm{W}$-типом (West). Типы Вангенгейма не содержат количественных характеристик интенсивности процесса.

Поиску связей между изменениями общей циркуляции атмосферы и изменением климата в настоящее время уделяется большое внимание [20, $22,23,24,26]$.

\section{РЕЗУЛЬТАТЫ}

\section{Вариации температуры и осадков}

Естественно принять, что климатические особенности распределения температуры и осадков по территории Северного Казахстана являются основой для их последующей трансформации, вызываемой изменением климата. Распределение температуры на метеостанциях региона позволяет оценить, что он характеризуется суровой зимой (среднемесячные температуры в январе составляют $-18{ }^{\circ} \mathrm{C}$ ) и жарким летом (среднемесячные температуры в июле равны $19-21^{\circ} \mathrm{C}$ ). Зимние температуры увеличиваются к северу и востоку. Самая низкая температура января имеет место в Петропавловске и Щербакты $\left(-17,9{ }^{\circ} \mathrm{C}\right)$, соответственно. За исключением февраля и марта, самая низкая месячная температура наблюдается и в Петропавловске. В результате здесь отмечается самая низкая среднегодовая температура $\left(1^{\circ} \mathrm{C}\right)$.

В январе и феврале самая высокая температура наблюдается в Кокшетау из-за его высокого положения над морем. С марта по июнь область самых высоких температур смещается на запад до Костаная, с мая она перемещается на северо-восток в район Павлодара. Согласно литературным источникам $[1,2,4]$ особенности общей циркуляции в атмосфере могут объяснить особенности этого движения. Однако это не предмет исследования. Следует отметить, что пространственная изменчивость среднемесячных температур не превышает $2,5^{\circ} \mathrm{C}$, и в большинстве месяцев она остается в пределах $2^{\circ} \mathrm{C}$, т.е. регион Северного Казахстана характеризуется довольно высокой и однородной температурой в течение года.

Среднегодовое количество осадков в регионе [10] составляет примерно 350 мм (в Петропавловске - 356 мм), а возможное испарение колеблется от 800 до 900 мм, превышая количество выпадающих осадков в два раза. Межгодовая изменчивость количества осадков тоже велика, она может превышать $50 \%$ от годовой нормы. Поэтому Северный Казахстан относят к зоне рискованного сельского хозяйства.

И несмотря на это в регионе сосредоточена основная сельскохозяйственная деятельность (земледелие), поскольку осадки выпадают в основном в вегетационный период: с мая по август выпадает более половины осадков.

Наибольшее годовое количество осадков выпадает в северной части региона (Петропавловск, 356 мм) и медленно уменьшается к югу (Нур-Султан, 342 мм). Значительное количество осадков отмечается также на северо-западе территории (Костанай, 331 мм). К востоку количество осадков быстро уменьшается, до 268 мм в Павлодаре. В течение вегетационного периода распределение 


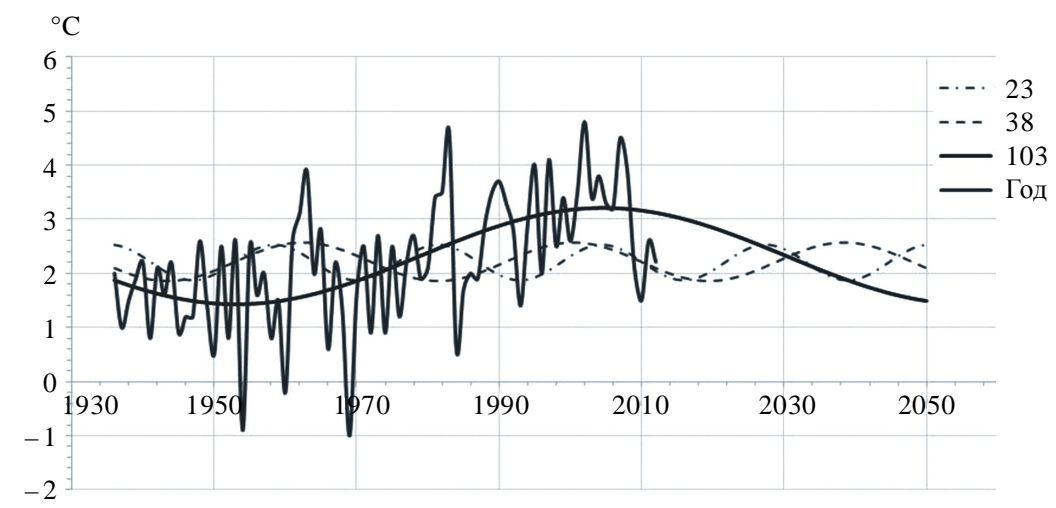

Puc. 1. Станция Щербакты. Результаты гармонического анализа временного ряда температур и экстраполяция гармоник на перспективу

Таблица 1

Продолжительность (годы) и амплитуда $\left({ }^{\circ} \mathrm{C}\right)$ гармоник в рядах температуры станций Северного Казахстана

\begin{tabular}{|c|c|c|c|c|c|c|c|}
\hline \multirow[b]{3}{*}{ Станции } & \multicolumn{7}{|c|}{ гармоники } \\
\hline & \multicolumn{3}{|c|}{ первая } & \multicolumn{2}{|c|}{ вторая } & \multicolumn{2}{|c|}{ третья } \\
\hline & 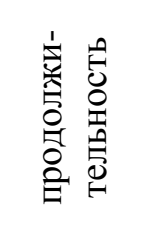 & 胥 & 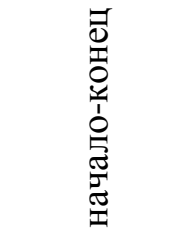 & 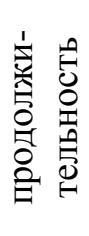 & 胥 & 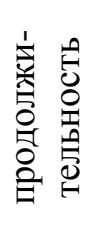 & 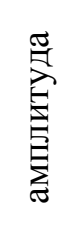 \\
\hline Кокшетау & $148 / 114$ & 2,8 & $2003 / 1946$ & 38 & 0,9 & 23 & 0,8 \\
\hline Костанай & $233 / 122$ & 2,6 & $2004 / 1943$ & 38 & 1,2 & 23 & 0,8 \\
\hline $\begin{array}{c}\text { Астана } \\
\text { (Нур-Султан) }\end{array}$ & 198/106 & 2,6 & $2005 / 1952$ & 38 & 1,2 & 23 & 0,8 \\
\hline Павлодар & $93 / 100$ & 1,6 & $203 / 1953$ & 38 & 0,6 & 23 & 0,8 \\
\hline Щербакты & $103 / 98$ & 1,8 & $2002 / 1953$ & 38 & 0,7 & 23 & 0,7 \\
\hline Явленка & $180 / 118$ & 1,9 & $2004 / 1945$ & 39 & 0,8 & 24 & 0,8 \\
\hline Петропавловск & $173 / 120$ & 2,1 & $2003 / 1943$ & 39 & 0,8 & 24 & 0,8 \\
\hline Среднее & $-/ 110$ & 2,2 & $\%$ & 38 & 0,9 & 23 & 0,8 \\
\hline
\end{tabular}

осадков по всей территории аналогично, но в северной части, где максимум имеет место, количество осадков составляет более $50 \%$ от годовой нормы. В целом, несмотря на ежегодные различия в осадках (до 88 мм), годовой режим их изменений очень схож. Таким образом, распределение температуры, определяющее испаряемость, и особенности выпадения осадков в течение года позволяют вести сельское хозяйство в регионе. Отклонения от этих условий, прежде всего уменьшение количества осадков в течение вегетационного периода в отдельные годы, приводит к потере урожая. При изменении климата в сторону высоких температур и малого количества осадков могут возникнуть условия при которых заниматься сельским хозяйством в этом регионе будет проблематичным. Поэтому необходимо разработать некото- рые сценарии возможного изменения температуры и количества осадков на период до 20402050 года на перспективу.

\section{Гармонический анализ}

Tемпература. В таблице 1 приведены результаты гармонического анализа рядов температуры на станциях региона. Результаты гармонического анализа временного ряда температуры на станции Щербакты приведены на рисунке 1.

Характеристики первых трех гармоник, выбирающих около $90 \%$ дисперсии временного ряда, приведены в таблице 3. Согласно гармоническому анализу, длительность первых гармоник колеблется от 100 до 220, ошибки, вызванные недостаточной длиной ряд, а составляют от 2 до $10 \%$. Для первых гармоник реальная продолжительность и фактическая продолжительность вековых циклов 


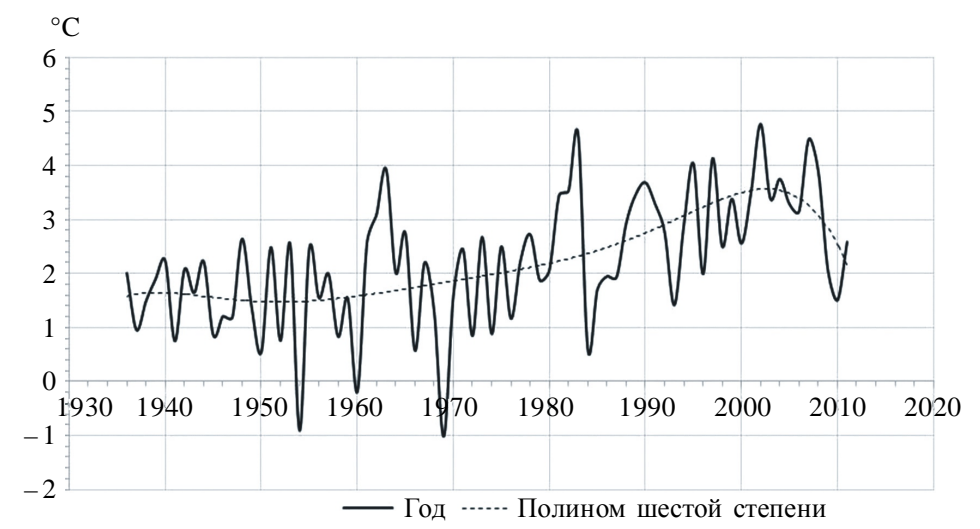

Puc. 2. Временной ряд температуры станции Щербакты

Таблица 2

Продолжительность (годы) и амплитуда (мм) гармоник в рядах осадков станций Северного Казахстана

\begin{tabular}{|c|c|c|c|c|c|c|}
\hline \multirow[b]{3}{*}{ Станции } & \multicolumn{6}{|c|}{ гармоники } \\
\hline & \multicolumn{2}{|c|}{ первая } & \multicolumn{2}{|c|}{ вторая } & \multicolumn{2}{|c|}{ третья } \\
\hline & 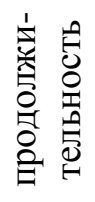 & 㞼 & 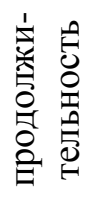 & 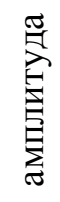 & 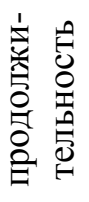 & 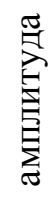 \\
\hline Кокшетау & - & - & 28 & 60 & 18 & 55 \\
\hline Костанай & 38 & 30 & 23 & 45 & 8 & 10 \\
\hline $\begin{array}{l}\text { Астана } \\
\text { (Нур-Султан) }\end{array}$ & 43 & 50 & 28 & 50 & 23 & 40 \\
\hline Павлодар & - & - & - & - & 15 & 25 \\
\hline Щербакты & 103 & 10 & 33 & 30 & & \\
\hline Явленка & 48 & 40 & - & - & 18 & 45 \\
\hline Петропавловск & 39 & 40 & 24 & 50 & 12 & 25 \\
\hline
\end{tabular}

в рядах температур были найдены по результатам полиномиальной аппроксимации. Он не содержит указанной ошибки. Это подтверждается всеми тремя гармониками.

Из таблицы 1 можно видеть, что длины первых гармоник уже немного отличаются. Наличие второй и третьей гармоник усложняет ситуацию. Длина реальных циклов (знаменатель) определяется на основе аппроксимации температурных временных рядов полиномом шестой степени. Можно видеть, что реальные вековые циклы не остаются постоянными и на всей территории. Они являются самыми длинными в центральной и западной частях региона и коррелируют с длинами первых гармоник.

В качестве примера, временной ряд температуры на станции Щербакты приведен на рисунке 2 .

В этом случае амплитуды всех трех гармоник начали уменьшаться почти однвременно (рис. 1), и расхождение между первыми гармониками на основе гармонического анализа и реальной кривой полинома шестой степени почти отсутствует.

Амплитуды первых гармоник на всех станциях колеблются от 1,6 до $2,8^{\circ} \mathrm{C}$. Длительность вторых гармоник составляет 38 лет с амплитудами от 0,6 до $1,2^{\circ} \mathrm{C}$. Третьи гармоники имеют период, равный 23 годам, с амплитудами $0,8^{\circ} \mathrm{C}$.

На севере региона вторая и третья гармоники на один год были длиннее, чем в норме, но это не имеет принципиального значения.

Кроме того, годы начала и конца реальных (первых) гармоник на станциях региона приведены в таблице 1. Видно, что начало потепления растянулось примерно на 10 лет, в то время как его окончание состоялось в два или три года. Эта изменчивость появления экстремального, в данном случае температурного минимума, является следствием изменчивости метеорологических процессов в регионе. 
Продолжительность (годы) и амплитуда (мм) циклов в рядах осадков по данным аппроксимации полиномом шестой степени

\begin{tabular}{|l|c|c|c|c|c|}
\hline \multicolumn{1}{|c|}{ Станции } & $\begin{array}{c}\text { годы } \\
\max \end{array}$ & $\begin{array}{c}\text { год } \\
\text { min }\end{array}$ & $\begin{array}{c}\text { продолжи- } \\
\text { тельность }\end{array}$ & $\begin{array}{c}\text { длины } \\
\text { полупериодов }\end{array}$ & амплитуда \\
\hline Кокшетау & 1965,2004 & 1985 & 39 & $20 / 19$ & 50 \\
\hline Костанай & 1954,2000 & 1976 & 46 & $22 / 24$ & 30 \\
\hline $\begin{array}{l}\text { Астана } \\
\text { (Нур-Султан) }\end{array}$ & 1962,2005 & 1986 & 43 & $24 / 19$ & 50 \\
\hline Павлодар & 1940,1998 & 1966 & 58 & $26 / 32$ & 60 \\
\hline Щербакты & 1946,2000 & 1976 & 54 & $30 / 24$ & 20 \\
\hline Явленка & 1946,1996 & 1968 & 50 & $22 / 18$ & 50 \\
\hline Петропавловск & 1952,1994 & 1970 & 42 & $18 / 24$ & 40 \\
\hline Среднее & 1952.2000 & 1975 & 47 & $23 / 23$ & 43 \\
\hline
\end{tabular}

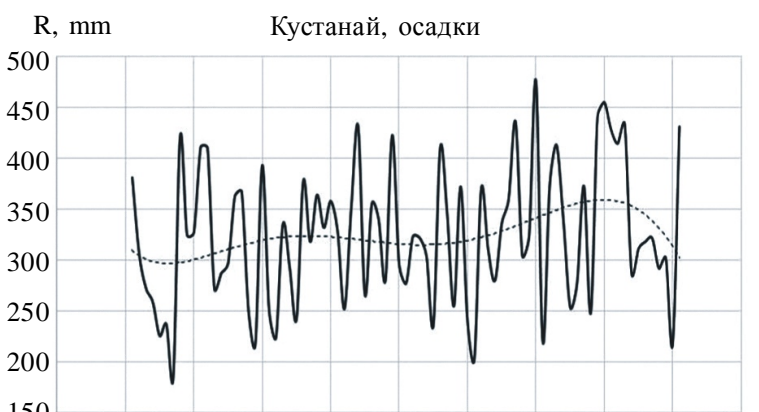

150

19201930194019501960197019801990200020102020
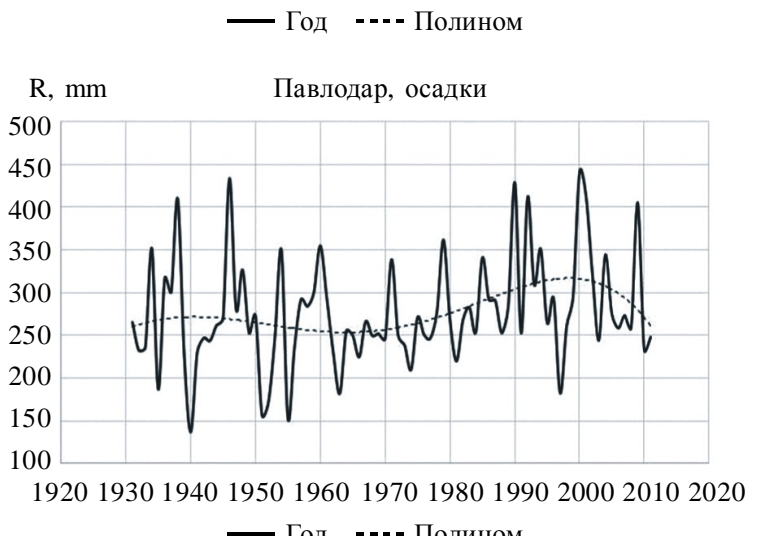

- Год --- Полином

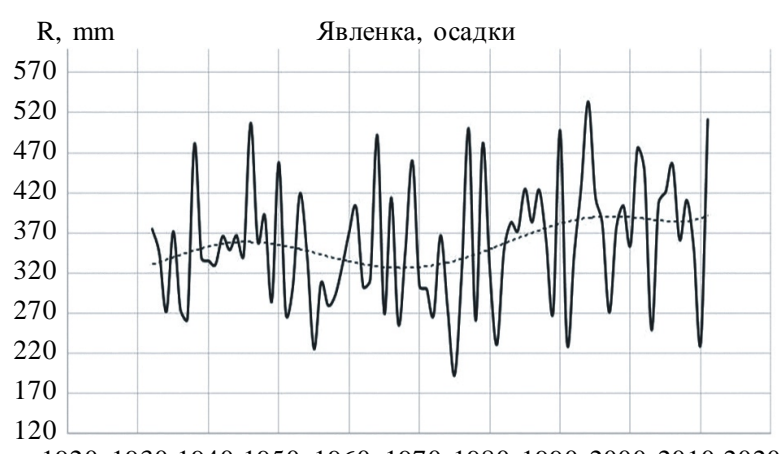

19201930194019501960197019801990200020102020 - Год --- Полином

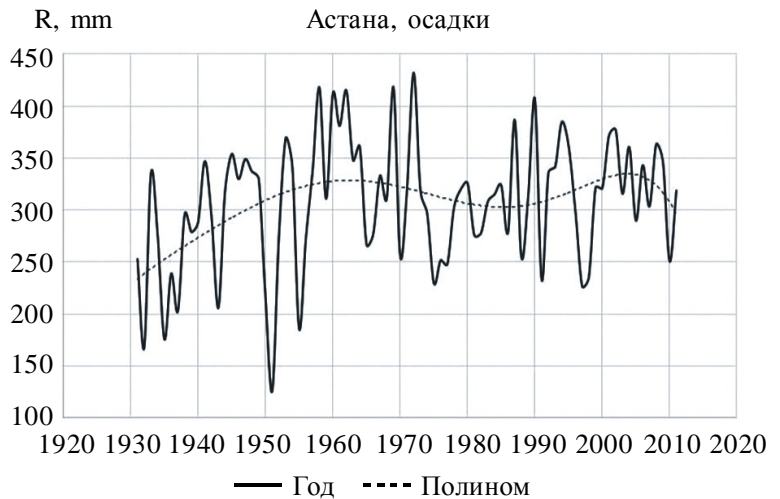

Puс. 3. Временные ряды осадков на станциях области, аппроксимированные полиномом шестой степени

Осадки. Рассмотрим далее временные ряды осадков (таблица 2).

Если температура существует постоянно, то осадки являются дискретным явлением. Кроме того, осадки сильно зависят от орографии. Естественно, что гармоники в рядах осадков на рассматриваемой территории оказались другими, чем гармоники в рядах температуры. Так, можно видеть, что в рядах осадков отсутствуют вековые гармоники. На большинстве станций есть только полувековые (Brikner) гармоники. Вековая гармоника была обнаружена только на стан- ции Щербакты, что является скорее результатом сложения двух полувековых гармоник, как это часто бывает [12-15]. Длина второй гармоники колеблется от 23 до 33 лет, а третьей - от 12 до 28 лет. Иногда амплитуды первой и второй гармоник примерно равны. Это хорошо видно на примере Северного Казахстана. Амплитуды первой и второй гармоник находятся в пределах 6030 мм. Амплитуды третьей гармоники немного меньше.

Из-за дисперсии длин и амплитуд гармоник в рядах осадков были проанализированы кривые, 
Результаты гармонического анализа временных рядов типов циркуляции

\begin{tabular}{|c|c|c|c|c|c|c|}
\hline \multirow{2}{*}{$\begin{array}{c}\text { Номера } \\
\text { гармоник }\end{array}$} & \multicolumn{9}{|c|}{ типы } & \multicolumn{2}{|c|}{ С } & \multicolumn{2}{|c|}{} \\
\cline { 2 - 7 } & $\begin{array}{c}\text { длина, } \\
\text { годы }\end{array}$ & $\begin{array}{c}\text { амплитуда, } \\
\text { дни }\end{array}$ & $\begin{array}{c}\text { длина, } \\
\text { годы }\end{array}$ & $\begin{array}{c}\text { амплитуда, } \\
\text { дни }\end{array}$ & $\begin{array}{c}\text { длина, } \\
\text { годы }\end{array}$ & $\begin{array}{c}\text { амплитуда, } \\
\text { дни }\end{array}$ \\
\hline 1 & 98 & 60 & 58 & 40 & 103 & 65 \\
\hline 2 & 43 & 40 & 28 & 25 & 38 & 40 \\
\hline 3 & 23 & 20 & 18 & 20 & 23 & 5 \\
\hline
\end{tabular}

которыми мы аппроксимировали временные ряды осадков (таблица 3 и рис. 3).

Следует отметить, что существует много сходств аппроксимирующих кривых осадков для всех станций. Однако, несмотря на эти сходства, видно, что существует несколько различий. Так, время наступления экстремумов в рядах значительно отличается для разных станций (таблица 3). Продолжительность циклов также неодинакова. Таким образом, во всех временных рядах легко определяются полувековые циклы длительностью от 39 до 58 лет. В то же время, если цикл начался в начале 50-60-х годов прошлого века, то он длиннее. Поэтому самый длинный цикл был в Павлодаре, который начался в 1940 году, а самый короткий - в Кокшетау, который начался в 1965 году, т.е. через 25 лет спустя.

Полуциклы внутри циклов тоже не одинаковы. Длительность цикла влияет на разницу между длинами полуциклов.

Из-за большой пространственной изменчивости осадков ряд авторов предлагает различные способы улучшения прогноза осадков на перспективу. Так, авторы $[3,4,11,16]$ предлагают метод осреднения количества осадков в регионе и использование этой характеристики для создания сценариев их климатического изменения. Однако в [5, 7] показано, что прогноз на основе среднего значения для ареала может быть источником ряда ошибок и искажений.

\section{Климатический прогноз}

Авторы метода динамической климатологии и вероятностного и статистического метода климатического прогноза $[3,4,11,16]$ предлагают концепцию аналоговой группы или группы «ближайших соседей». «Ближайшие соседи» - это те, которые имеют сходные режимы температуры и количества осадков. Выше было показано, что динамика рядов температуры мало отличается по территории, и режим осадков, несмотря на их большую изменчивость, тоже сходен. Поэтому в нашем регионе может быть применена концепция «ближайших соседей».

Сценарий изменения температуры. Создание сценария на перспективу возможно на основе гармонического анализа временного ряда температуры на станции Щербакты. В предположении, что гармоники в температурном временном ряду в Щербакты сохранятся, можно продлить их на перспективу до 2050 года. В этом случае следует ожидать, что температура в течение следующих 50 лет за счет вековой гармоники будет понижаться в пределах своей амплитуды, около $2^{\circ} \mathrm{C}$ к концу периода. Этот процесс приведет к снижению общей климатической температуры. За счет влияния второй и третьей гармоник это понижение будет происходить с некоторыми колебаниями (не более $\left.0,8^{\circ} \mathrm{C}\right)$.

На северо-востоке и в северных районах региона падение температуры произойдет раньше, чем в центральном и южном регионах. Климатическое различие температур по всей территории не превысит $2^{\circ} \mathrm{C}$.

Сценарий изменения осадков. Мы использовали два подхода. Первый подход состоял в том, чтобы использовать гармонический анализ временных рядов осадков и построить на этой основе временной ход осадков на будущее. Этот подход аналогичен тому, как мы построили сценарий изменения температуры климата, и поэтому мы здесь не останавливаемся. Недостатком такого подхода показалось, что гармоники во временных рядах осадков, в отличие от временных рядов температуры, сходятся медленно. Каждый случай осадков (импульсов) характеризуется очень малой корреляцией между длительностью импульсов и периодом повторения. Размер этого периода длиннее длительности импульсов, что приводит к медленной конвергенции ряда. Необходимо учитывать большее количество гармоник (чем для температуры) из-за того, что амплитуды соседних гармоник близки (таблица 2). Согласно теории гармо- 

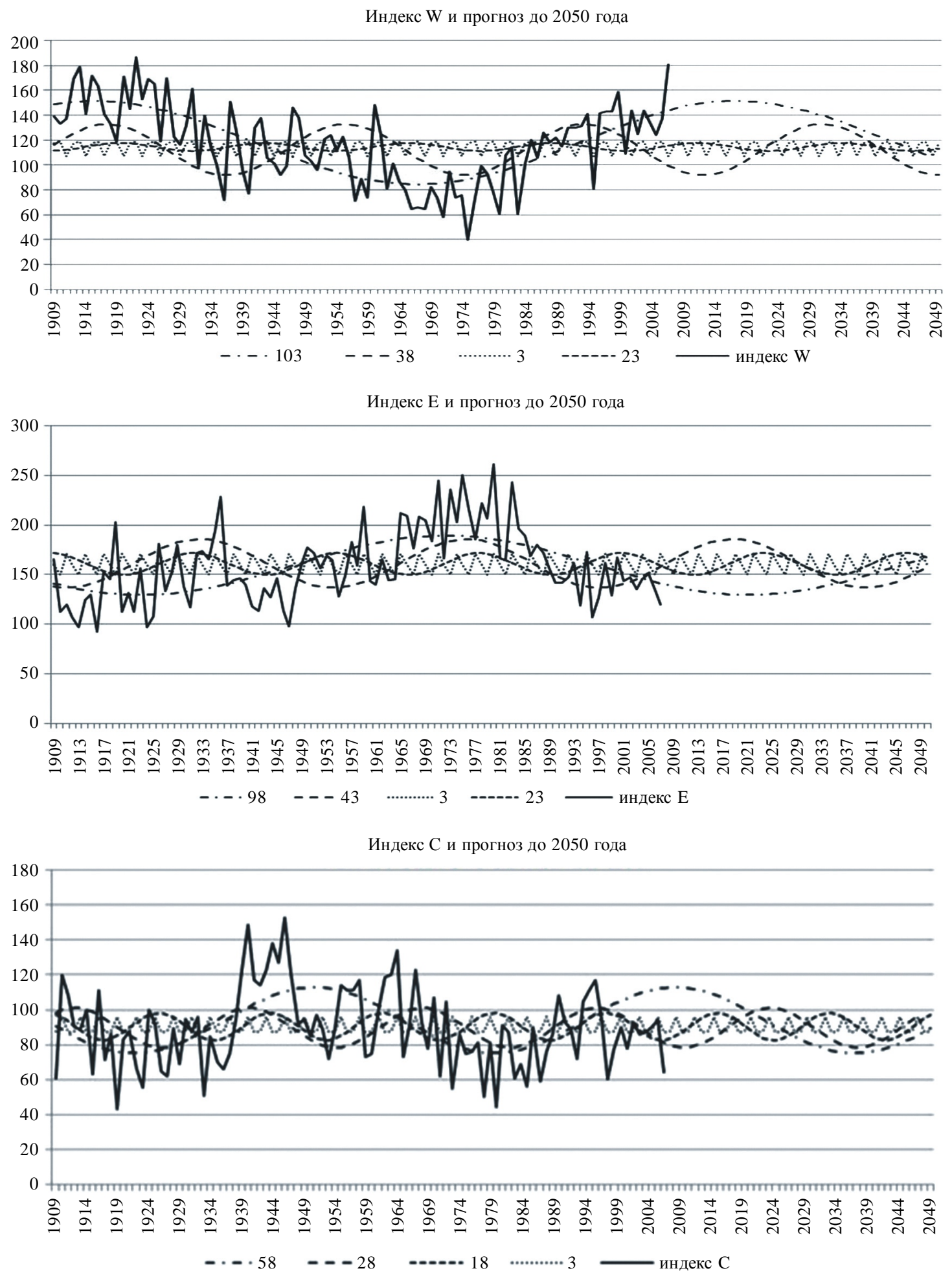

Puc. 4. Результаты гармонического анализа временных рядов общей циркуляции атмосферы с прогнозом до 2050 года

нического анализа [32], «..Ряды Фурье более подходят для анализа временных рядов, чем для синтеза и создания прогнозирующих сценариев». На самом деле это не так, использование их для построения климатических сценариев возможно.
Поэтому для создания сценариев динамики осадков на перспективу была использована связь между временными рядами осадков и компонентами общей циркуляции в атмосфере (типы макропроцессов). Корреляционные связи между по- 


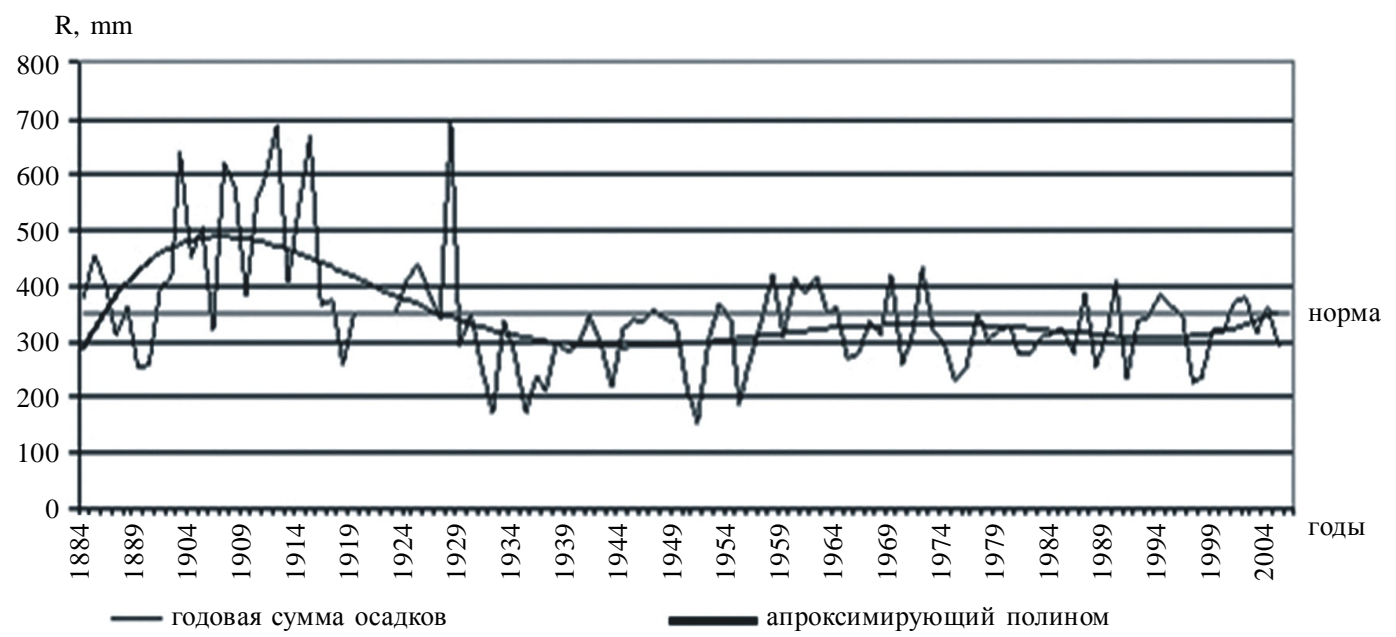

Puc. 5. Станция Астана (Нур-Султан). Временный ряд осадков

вторяемостью макропроцессов (или их комбинацией), с одной стороны, и количеством осадков с другой стороны в регионе были установлены нами ранее [12-15]. Для этого необходимо было провести гармонический анализ типов макропроцессов. Результаты такого анализа приведены в таблице 4 и на рисунке 4.

Согласно таблице 4 и рисунку 4 видно, что более $90 \%$ дисперсии на всех типах выбраны первыми тремя гармониками, а при макротипе $\mathrm{W}-$ двумя. Из анализа гармоник всех трех типов циркуляции следует, что все они быстро сходятся, что подразумевает наличие в них высокой внутренней и физической взаимозависимости и когерентность ряда. [15]. Этот факт позволяет нам использовать их для создания сценария изменения осадков в будущем.

Тип W содержит первую вековую гармонику (103 года) и ее амплитуда равна 65 дням. Вторая гармоника длится 38 лет и имеет амплитуду 40 дней, а третья - 23 года, а ее амплитуда составляет всего около 5 дней. Фактически, третья гармоника в типе $\mathrm{W}$ может не рассматриваться в анализе из-за ее малого вклада в общую дисперсию.

Во временном ряде типа Е тоже есть вековая гармоника (98 лет) с амплитудой, равной 60 дням, вторая гармоника длится 43 года и с амплитудой, равной 40 дням, а третья гармоника имеет продолжительность 23 года с амплитудой, равной 20 дням.

Во временном ряде типа С отсутствует вековая гармоника. Самая длинная - это гармоника 58 лет с амплитудой 40 дней. Вторая гармоника длится 28 лет и имеет амплитуду 25 дней. Третья гармоника длится 18 лет и ее амплитуда составляет около 20 дней.
Гармоники в типе $\mathrm{C}$ имеют самые малые амплитуды (в два раза по сравнению с соответствующими гармониками других типов), они также имеют и наименьшую продолжительность.

В результате совместного анализа гармоник в рядах осадков и гармоник по типам в общей циркуляции атмосферы были получены сценарии ожидаемых климатических изменений в количестве осадков в регионе. Они следующие.

Ход осадков с небольшими климатическими колебаниями имеет максимум внастоящее время, который повторится в тридцатые годы XXI, а наиболее вероятная амплитуда колебаний ( \pm 20 мм от нормы).

Сравнивая полученные результаты, с результатами, полученными путем экстраполяции и сложения основных гармоник в рядах осадков, против ожидания, мы обнаружили, что результаты, полученные двумя разными способами, близки. Однако использование показателей общей циркуляции позволяет нам понять физическую сторону процессов, которые формируют экстремальные климатические условия.

Рассмотрим далее временной ход осадков на станции Астана (Нур-Султан) в связи с динамикой показателей общей циркуляции атмосферы.

Самый длинный временных ряд осадков в регионе имеет место на станции Астана. Анализируя временные ряды осадков, можно видеть, что начало XX века характеризовалось максимальными осадками (рис. 5). Этот климатический максимум (до 500 мм в отдельные годы) был достаточно выражен, чтобы обеспечить отрицательную линейную тенденцию в течение остальной части $\mathrm{XX}$ века. Некоторые ученые, начиная с этого времени, начали считать, что глобальное потепление привело к уменьшению количества осадков в ре- 
Характеристика гармоник типов макропроцессов при экстремумах осадков в Астане (Нур-Султане)

\begin{tabular}{|c|c|c|c|c|c|}
\hline \multirow{2}{*}{$\begin{array}{c}\text { Типы } \\
\text { процессов }\end{array}$} & \multirow{2}{*}{$\begin{array}{c}\text { номера } \\
\text { гармоник }\end{array}$} & \multicolumn{4}{|c|}{ экстремумы, годы } \\
\hline & & $\begin{array}{c}\text { максимум } \\
\text { около } 1908\end{array}$ & $\begin{array}{c}\text { минимум } \\
\text { около } 1944\end{array}$ & $\begin{array}{c}\text { максимум } \\
\text { около } 1974\end{array}$ & $\begin{array}{c}\text { минимум } \\
\text { около } 2002\end{array}$ \\
\hline \multirow[t]{3}{*}{$\mathrm{E}$} & 1 & $\begin{array}{l}\text { на спаде, } \\
\text { ниже нормы }\end{array}$ & $\begin{array}{l}\text { на подъеме, } \\
\text { около нормы }\end{array}$ & в максимуме & $\begin{array}{l}\text { на спаде, } \\
\text { около нормы }\end{array}$ \\
\hline & 2 & $\begin{array}{l}\text { ниже нормы, } \\
\text { около } \\
\text { минимума }\end{array}$ & $\begin{array}{l}\text { на спаде, } \\
\text { около нормы }\end{array}$ & в максимуме & $\begin{array}{l}\text { около } \\
\text { минимума, на } \\
\text { спаде, ниже } \\
\text { нормы }\end{array}$ \\
\hline & 3 & $\begin{array}{l}\text { около } \\
\text { максимума }\end{array}$ & в минимуме & в максимуме & \begin{tabular}{|l} 
на подъеме, \\
выше нормы
\end{tabular} \\
\hline \multirow[t]{3}{*}{$\mathrm{C}$} & 1 & $\begin{array}{l}\text { на спаде, } \\
\text { ниже нормы }\end{array}$ & $\begin{array}{l}\text { рост, близко } \\
\text { к максимуму }\end{array}$ & $\begin{array}{l}\text { близка к } \\
\text { минимуму, } \\
\text { спад } \\
\end{array}$ & $\begin{array}{l}\text { на подъеме, } \\
\text { выше нормы }\end{array}$ \\
\hline & 2 & $\begin{array}{l}\text { на спаде, } \\
\text { около } \\
\text { максимума }\end{array}$ & $\begin{array}{l}\text { рост, в } \\
\text { максимуме }\end{array}$ & $\begin{array}{l}\text { на спаде, } \\
\text { около нормы }\end{array}$ & в максимуме \\
\hline & 3 & $\begin{array}{l}\text { на спаде, } \\
\text { выше нормы }\end{array}$ & $\begin{array}{l}\text { максимум, } \\
\text { спад }\end{array}$ & $\begin{array}{l}\text { на подъеме, } \\
\text { около нормы }\end{array}$ & в максимуме \\
\hline \multirow[t]{3}{*}{$\mathrm{W}$} & 1 & $\begin{array}{l}\text { на подъеме, } \\
\text { около } \\
\text { максимума } \\
\end{array}$ & $\begin{array}{l}\text { на спаде, } \\
\text { около нормы }\end{array}$ & $\begin{array}{l}\text { около } \\
\text { минимума }\end{array}$ & $\begin{array}{l}\text { на подъеме, } \\
\text { выше нормы }\end{array}$ \\
\hline & 2 & $\begin{array}{l}\text { на подъеме от } \\
\text { минимума }\end{array}$ & $\begin{array}{l}\text { на подъеме, } \\
\text { около нормы }\end{array}$ & \begin{tabular}{|l|} 
спад, затем \\
около \\
минимума \\
\end{tabular} & $\begin{array}{l}\text { на спаде, } \\
\text { около нормы }\end{array}$ \\
\hline & 3 & $\begin{array}{l}\text { на подъеме от } \\
\text { минимума }\end{array}$ & около нормы & $\begin{array}{l}\text { около } \\
\text { минимума }\end{array}$ & около нормы \\
\hline
\end{tabular}

гионе [16, 17]. И такое понижение началось с двадцатых годов прошлого века.

Попробуем определить, какие макросиноптические условия сформировали максимум осадков в Астане (Нур-Султане) в начале ХХ века. Результаты анализа приведены в таблице 5.

Видно, что климатический максимум имел место в 1908 году, когда все три гармоники типа W были в максимуме или близко к нему. Первая гармоника типа С была в состоянии понижения и ниже нормы, а вторая и третья были также на рецессии, но в любом случае выше нормы.

Первая и вторая гармоники типа Е были в состоянии понижения и ниже нормы. Только третья гармоника была максимальной.

Поэтому максимум осадков в начале XX века в Астане (Нур-Султане) был обусловлен необычайно высокой активностью процессов типа W, a первая гармоника достигла своего максимума, а гармоники типов С и Е были слабо выражены.

Второй менее выраженный максимум осадков в семидесятых годах наблюдался, когда все три гармоники типа Е приближались к максимуму, а гармоники типов С и W были слабо выражены. Поэтому в семидесятые годы максимум осадков имел место при выраженной активности всех трех гармоник типа Е.

В сороковые годы XX века минимальные осадки имели место при высокой активности типа $\mathrm{C}$ : все три гармоники были в максимуме или около него. Активность типов Е и W была вялой (таблица 5). Поэтому минимум осадков в Астане (НурСултане) был обусловлен высокой активностью типа С и активностью около нормы типов Е и W.

Минимальный уровень осадков в конце XX века наблюдался и при гиперактивности типа C: вторая и третья гармоники были в максимуме, а первая - в состоянии роста. Вторая и третья гармоники типа W были на спаде по норме, а первая поднималась, но оставалась вблизи нормы. Примерно такой же была активность типа Е (таблица 5).

Поэтому в XX веке максимум осадков имел место при типах W и E, а минимальные осадки наблюдались при типе C. 


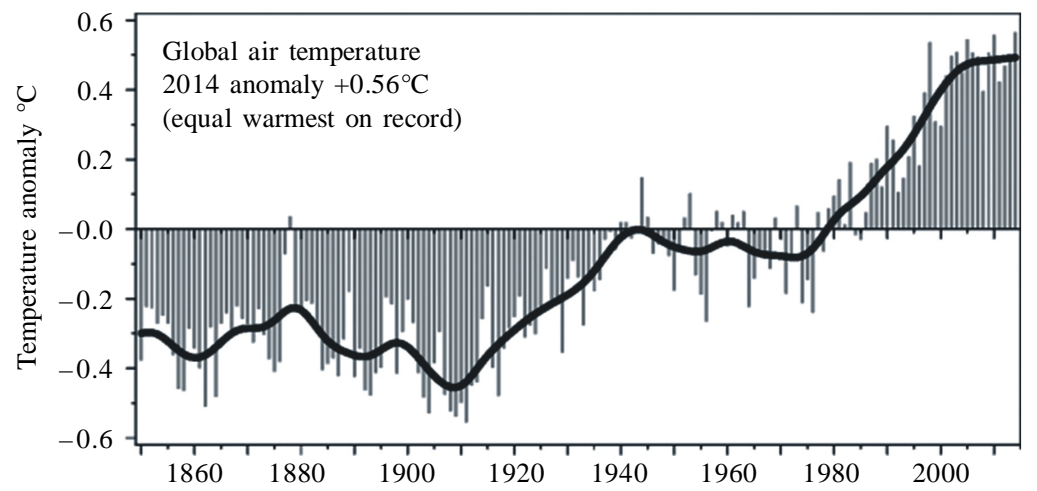

Puc. 6. Динамика глобальной температуры воздуха (http://www.cru.uea.ac.uk/) [18]

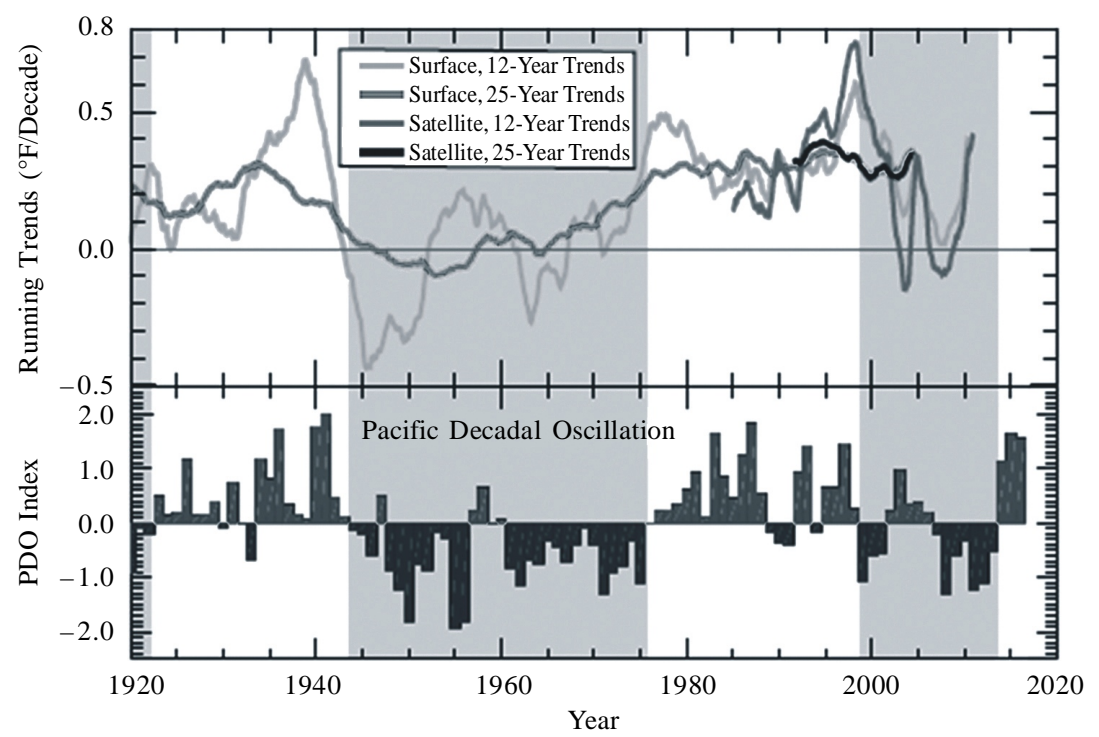

Puc. 7. Динамика температуры поверхностных вод в Тихом океане (doi: 10.7930 / J0J964J6) [18]

Было замечено, когда гармоники соответствующих типов находятся в стадии роста, это приводит к росту осадков. Напротив, когда те же гармоники находятся на спаде, это не сильно влияет на осадки.

\section{ОБСУЖДЕНИЕ РЕЗУЛЬТАТОВ}

Мы построили климатический прогноз ожидаемого климатического изменения температуры и осадков с использованием разных методов, но на основе физических связей.

Невозможно проанализировать изменение климата в конкретном регионе, не сравнивая результаты с процессами в Северном полушарии, с глобальными процессами. Рассмотрим данные Европейского центра по среднесрочным прогнозам (рис. 6).

Видно, что во второй половине XX века повсеместно наблюдалась положительная температурная тенденция. Добавив последние два года, авто- ры несколько приподняли конец аппроксимирующей кривой, что, однако, не изменило факта замедления процесса роста температуры (hiatus). O прекращении роста глобальной температуры воздуха сообщается в ряде работ [21, 24, 25, 28-30]. Когда глобальная температура стабилизируется, вполне можно наблюдать ее понижение в отдельном регионе (нашем). В этой связи интересное исследование содержится в [18, 32], оно включено в Четвертое национальное сообщение Соединенных Штатов [31]. Авторы изучали динамику температуры поверхности Тихого океана (рис. 7)

Известно, что температура поверхности воды Тихого океана и океанских течений Эль-Ниньо и Ла-Ниньо определяют глобальную крупномасштабную циркуляцию атмосферы [23, 28, 30], peзультаты таких исследований важны. Авторы пришли к выводу, что температура поверхности Тихого океана испытывает периодические колебания 
(рис. 7). Это подтверждает целесообразность используемого нами гармонического анализа для изучения временных рядов температуры и осадков. В динамике временных рядов температуры поверхностных вод можно наблюдать цикличность с периодом около 50 лет. Такая цикличность выявляется нами, как и другими авторами [3, 4, 5, 9, $13,14,15,16]$ во временном ряду осадков. Кроме того, авторы $[18,32]$ отмечают, что замедление роста температуры воды началось примерно в 1975 году, то есть задолго до такого же замедления динамики температуры воздуха. Примерно в то же время началось замедление меридиональной циркуляции (АМОК) в Северной Атлантике [18, 31]. Результаты, полученные в [18, 32], подтверждают определяющее влияние океана на температуру атмосферы и циркуляцию влаги через крупномасштабную циркуляцию атмосферы.

Вернемся в наш регион. Было интересно сравнить наши данные и прогноз изменения климата в Казахстане с данными других авторов. Так, в [8, 27] в конце XX и начале XXI века изменения температуры и количества осадков по территории Казахстана и Центральной Азии были предсказаны и описаны вероятностно и статистическими методами. Были предсказаны температура и количество осадков на территории, а также прогнозирующие факторы - коэффициент глобальной прозрачности, коэффициент оптической плотности, концентрация диоксида углерода, температура приземного воздуха в Северном полушарии. В то же время отношения между ними и их влиянием не обсуждались. В [14] нами было показано, что тот прогноз не оправдался. Часть связей интерпретировалась, как ложная.

В то же время в [9] с 2010 года было отмечено понижение температуры в Южной Сибири. Приблизительно в то же время температура на северо-востоке Казахстана тоже начала понижаться, было показано в [14]. Понижение климатической температуры в течение нескольких лет затем захватило всю республику.

Сейчас уже многие исследователи отмечают начало понижения климатической температуры на Евразийском континенте. Таким образом, Европейский центр среднесрочных прогнозов в [6], представляя динамику глобальной температуры в последние годы в виде почти горизонтальной линии, по сути, подтверждает, что в отдельных районах она может понижаться.

По данным гидрометеорологического центра России [6] за последние 10 лет температуры за- фиксировали нулевые тренды среднего значения не только на юго-западе Сибири, а мы - на всей территории Казахстана [14].

Из наших результатов следует, что климатический рост температуры не угрожает сельскому хозяйству в Северном Казахстане. Но, как отмечалось выше, территория принадлежит к зоне рискованного земледелия; два из пяти лет характеризуются неурожаем. Поэтому есть проблема адаптации к существующим климатическим условиям. Кроме того, борьба за сокращение выбросов парниковых газов является также борьбой за сокращение выбросов различных загрязняющих веществ в окружающую среду, борьбой за чистоту окружающей среды.

\section{ЗАКЛЮЧЕНИЕ}

По результатам выполненных исследований мы получили следующее.

1. Первые три гармоники, как правило, выбирают около $90 \%$ дисперсии во временных рядах температуры. Благодаря этому возможно создание сценариев на перспективу в предположении сохранения первых гармоник разложения.

2. Гармоники на метеорологических станциях в Северном Казахстане очень похожи. Это позволяет применять метод «ближайших соседей» и анализировать только одну станцию в группе.

3. В течение следующих 40 лет температура в Северном Казахстане понизится на величину амплитуды вековой гармоники, т.е. примерно на $2{ }^{\circ} \mathrm{C}$ к концу периода. Флуктуация климатической температуры под влиянием второй и третьей гармоник не будет превышать $0,8{ }^{\circ} \mathrm{C}$.

4. Гармоники во временных рядах осадков не обладают достаточной сходимостью, потому что очень малая связь между длительностью осадков и периодом их повторения. Размер периода повторения больше, чем длительность импульса; это приводит к медленной сходимости ряда и требует рассмотрения большего количества гармоник. В то же время гармоники в рядах осадков изменяются незначительно по всей территории, и это позволяет создать сценарий на основе метода «ближайших соседей». В отношении осадков целесообразнее использовать связи между климатическими изменениями осадков и колебаниями индексов общей циркуляции атмосферы.

Ход осадков с небольшими климатическими колебаниями имеет максимум сейчас и будет повторяться в тридцатые годы XXI. Наиболее вероятная амплитуда колебаний \pm 20 мм от нормы с его минимумом в 2020-2025 годах. 
5. Несмотря на то, что в ближайшие десятилетия ожидается падение температуры, способствующее снижению испарения в регионе, а осадки будут близки к норме, необходимо содействовать процессам адаптации в сельском хозяйстве, чтобы обеспечить устойчивость урожаев в условиях значительной межгодовой изменчивости осадков.

Исследование поддерживается Министерством науки и образования Республики Казахстан, проект АР05131867.

\section{СПИСОК ЛИТЕРАТУРЫ}

1. Бугаев В. А. Синоптические процессы Средней Азии / В. А. Бугаев, В. А. Джорджио, Е. М. Козик. Ташкент : Издательство АН Узбекской ССР, 1957. - 447 с.

2. Гирс А. А. Многолетние колебания атмосферной циркуляции и долгосрочные гидрометеорологические прогнозы / А. А. Гирс. - Ленинград : Гидрометеоиздат, 1971. $-488 \mathrm{c}$.

3. Груза Г. В. Вероятностные метеорологические прогнозы / Г. В. Груза, Э. Я. Ранькова. - Ленинград : Гидрометеоиздат, 1983. - 270 с.

4. Груза Г. В. Мониторинг и вероятностный прогноз короткопериодных колебаний климата / Г. В. Груза, Э. Я. Ранькова. - Ленинград : Гидрометеоиздат, 1989. - C. $148-170$.

5. Жильцова Е. Л. О точности воспроизведения температуры и осадков на территории России глобальным климатическим архивом / Е. Л. Жильцова, О. А. Анисимов // Метеорология и гидрология. - 2009. - № 10. C. 79-89.

6. Кокорин А. Н. Сайт программы «Климат и энергетика» - 2019. - [URL: https://wwf.ru/resources/ publications/booklets (дата обращения 9.04.2019).

7. О неопределенности некоторых сценарных климатических прогнозов температуры воздуха и осадков по территории и России / Г. В. Груза [и др.] // Метеорология и гидрология. -2006 . - № 10. - С. 5-23.

8. Пилифосова О. В. Вероятностный сверхдолгосрочный прогноз полей изменений сумм осадков в регионе «Казахстан-Средняя Азия» / О. В. Пилифосова // Труды Казахского регионального научно-исследовательского гидрометеорологического института. - 1991. Вып. 111. - С. 66-75.

9. Пилифосова О. В. О тенденциях изменения увлажнения территории Казахстана / О. В. Пилифосова // Труды Казахского регионального научно-исследовательского гидрометеорологического института. - 1990. Вып. 105. - С. 77-88.

10. Справочник по климату Казахстана : Многолетние данные. Атмосферные осадки. - Алматы : Казгидромет, 2005. - Вып. 1-14. - 243 с.

11. Схема вероятностного адаптивного метеорологического прогноза (групповые аналоги) с оптимизацией состава предикторов / Г. В. Груза [и др.] // Труды Гидрометцентра СССР. - 1989. - Вып. 306. - С. 3-55.
12. Чередниченко А. В. Временные ряды температуры и осадков. Статистический анализ / А. В. Чередниченко, А. В. Чередниченко, В. С. Чередниченко. Алматы : [б.и.], 2013. - 366 с.

13. Чередниченко А. В. Динамика климата Казахстана. Начало эпохи похолодания / А. В. Чередниченко. - Алматы : [б.и.], 2015. - 208 с.

14. Чередниченко А. В. О цикличности в рядах температур. Начало цикла похолодания / А. В. Чередниченко, А. В. Чередниченко, В. С. Чередниченко // Гидрометеорология и экология. - 2014. - № 2. - С. 7-16.

15. Чередниченко А. В. Современные климатические циклы во временных рядах температуры и осадков над Казахстаном / А. В. Чередниченко, А. В. Чередниченко, В. С. Чередниченко // Вестник Воронежского государственного университета. Сер. География. Геоэкология. - 2017. - № 4. - С. 15-34.

16. Climate change in the City of Almaty during the past 120 years / A. V. Cherednichenko [et al.] // Quaternary International journal. - 2015. - URL: www.elsevier.com/ locate/quaint (дата обращения : 9.04.2019).

17. Climate Science Special Report: Fourth National Climate Assessment / D. J. Wuebbles [et al.] // USGCRP, Global Change Research Program. - Washington, DC, USA. - 2017. - P. 470.

18. Climatic Research Unit - 2019. - URL : http:// www.cru.uea.ac.uk/ (дата обращения 9.04.2019).

19. Comparing tropospheric warming in climate models and satellite data / B. D. Santer [et al.] // Journal of Climate. - 2017. - Vol. 30. - P. 373-392.

20. Exceptional twentieth-century slowdown in Atlantic Ocean overturning circulation / S. Rahmstorf [et al.] // Nature Climate Change. - 2015. - Vol. 5. - P. 475-480.

21. Knutson T. R. Prospects for a prolonged slowdown in global warming in the early 21 st century / T. R. Knutson, R. Zhang, L. W. Horowitz // Nature Communications. 2016. - Vol. 7. - P. 136-176.

22. Kopp G. A new, lower value of total solar irradiance: Evidence and climate significance / G. Kopp, J. L. Lean // Geophysical Research Letters. - 2011. - Vol. 38. - L01706.

23. Langenbrunner B. Analyzing ENSO telecomnections in CMIP models as a measure of model fidelity in simulating precipitation / B. Langenbrunner, J. D. Neelin // Journal of Climate. - 2013. - Vol. 26. P. 4431-4446.

24. Lewandowsky $S$. The «pause» in global warming: Turning a routine fluctuation into a problem for science / S. Lewandowsky, J. S. Risbey, N. Oreskes // Bulletin of the American Meteorological Society. - 2016. - Vol. 97. P. 723-733.

25. Palmen E. Atmospheric circulation systems. Their structure and physical interpretation / E. Palmen, C. W. Newton. - New York; London : Academic press, 1969. $-615 \mathrm{p}$.

26. Schurer A. P. Small influence of solar variability on climate over the past millennium / A. P. Schurer, 
S. F. B. Tett, G. C. Hegerl // Nature Geoscience. - 2014. Vol. 7. - P. 104-108.

27. Sneyers R. On the statistical analysis of series of observations / R. Sneyers // Technical note. - 1990. - № 143. - P. 192.

28. Stevenson S. L. Significant changes to ENSO strength and impacts in the twenty-first century: Results from CMIP52012 / S. L. Stevenson // Geophysical Research Letters. - 2012. - Vol. 39. - L17703.

29. Testing for the possible influence of unknown climate forcings upon global temperature increases from 1950 to 2000 / B. T. Anderson [et al.] // Journal of Climate. - 2012. - Vol. 25. - P. 7163-7172.

30. The Northern Hemisphere extra tropical atmospheric circulation response to ENSO: How well do we know it and how do we evaluate models accordingly? / C. Deser[et al.] // Journal of Climate. - 2017. - Vol. 30. P. 5059-5082.

31. Trenberth K. E. Has there been a hiatus? / K. E. Trenberth // Science. - 2015. - Vol. 349. - P. 691-692.

32. Uncertainties in precipitation and their impacts on runoff estimates / B. M. Fekete [et al.] // Journal of Climate. - 2004. - Vol. 1. - P. 293-304.

\section{REFERENCES}

1. Bugaev V. A. Sinopticheskie protsessy Sredney Azii / V. A. Bugaev, V. A. Dzhordzhio, E. M. Kozik. - Tashkent : Izdatel'stvo AN Uzbekskoy SSR, 1957. - 447 s.

2. Girs A. A. Mnogoletnie kolebaniya atmosfernoy tsirkulyatsii i dolgosrochnye gidrometeorologicheskie prognozy / A. A. Girs. - Leningrad : Gidrometeoizdat, 1971.$488 \mathrm{~s}$.

3. Gruza G. V. Veroyatnostnye meteorologicheskie prognozy / G. V. Gruza, E. Ya. Ran'kova. - Leningrad : Gidrometeoizdat, 1983. - 270 s.

4. Gruza G. V. Monitoring i veroyatnostnyy prognoz korotkoperiodnykh kolebaniy klimata / G. V. Gruza, E. Ya. Ran'kova. - Leningrad : Gidrometeoizdat, 1989. S. 148-170.

5. Zhil'tsova E. L. O tochnosti vosproizvedeniya temperatury i osadkov na territorii Rossii global'nym klimaticheskim arkhivom / E. L. Zhil'tsova, O. A. Anisimov // Meteorologiya i gidrologiya. - 2009. - № 10. - S. 79-89.

6. Kokorin A. N. Sayt programmy «Klimat i energetika»-2019. - [URL: https://wwf.ru/resources/publications/ booklets (data obrashcheniya 9.04.2019).

7. O neopredelennosti nekotorykh stsenarnykh klimaticheskikh prognozov temperatury vozdukha i osadkov po territorii i Rossii / G. V. Gruza [i dr.] // Meteorologiya i gidrologiya. - 2006. - № 10. - S. 5-23.

8. Pilifosova O. V. Veroyatnostnyy sverkhdolgosrochnyy prognoz poley izmeneniy summ osadkov $\mathrm{v}$ regione «Kazakhstan-Srednyaya Aziya» / O. V. Pilifosova // Trudy Kazakhskogo regional'nogo nauchno-issledovatel'skogo gidrometeorologicheskogo instituta. - 1991. - Vyp. 111. S. 66-75.
9. Pilifosova O. V. O tendentsiyakh izmeneniya uvlazhneniya territorii Kazakhstana / O. V. Pilifosova // Trudy Kazakhskogo regional'nogo nauchno-issledovatel'skogo gidrometeorologicheskogo instituta. - 1990. - Vyp. 105. S. 77-88.

10. Spravochnik po klimatu Kazakhstana : Mnogoletnie dannye. Atmosfernye osadki. - Almaty : Kazgidromet, 2005. - Vyp. 1-14. - 243 s.

11. Skhema veroyatnostnogo adaptivnogo meteorologicheskogo prognoza (gruppovye analogi) s optimizatsiey sostava prediktorov / G. V. Gruza [i dr.] // Trudy Gidromettsentra SSSR. - 1989. - Vyp. 306. - S. 3-55.

12. Cherednichenko A. V. Vremennye ryady temperatury i osadkov. Statisticheskiy analiz / A. V. Cherednichenko, A. V. Cherednichenko, V. S. Cherednichenko. Almaty : [b.i.], 2013. - 366 s.

13. Cherednichenko A. V. Dinamika klimata Kazakhstana. Nachalo epokhi pokholodaniya / A. V. Cherednichenko. - Almaty : [b.i.], 2015. - 208 s.

14. Cherednichenko A. V. O tsiklichnosti v ryadakh temperatur. Nachalo tsikla pokholodaniya / A. V. Cherednichenko, A. V. Cherednichenko, V. S. Cherednichenko // Gidrometeorologiya i ekologiya. - 2014. - № 2. - S. 7-16.

15. Cherednichenko A. V. Sovremennye klimaticheskie tsikly vo vremennykh ryadakh temperatury i osadkov nad Kazakhstanom / A. V. Cherednichenko, A. V. Cherednichenko, V. S. Cherednichenko// Vestnik Voronezhskogo gosudarstvennogo universiteta. Ser. Geografiya. Geoekologiya. - 2017. - № 4. - S. 15-34.

16. Climate change in the City of Almaty during the past 120 years / A. V. Cherednichenko [et al.] // Quaternary International journal. - 2015. - URL: www.elsevier.com/ locate/quaint (data obrashcheniya : 9.04.2019).

17. Climate Science Special Report: Fourth National Climate Assessment / D. J. Wuebbles [et al.] // USGCRP, Global Change Research Program. - Washington, DC, USA. - 2017. - P. 470.

18. Climatic Research Unit - 2019. - URL : http:// www.cru.uea.ac.uk/ (data obrashcheniya 9.04.2019).

19. Comparing tropospheric warming in climate models and satellite data / B. D. Santer [et al.] // Journal of Climate. - 2017. - Vol. 30. - P. 373-392.

20. Exceptional twentieth-century slowdown in Atlantic Ocean overturning circulation / S. Rahmstorf [et al.] // Nature Climate Change. - 2015. - Vol. 5. - P. 475-480.

21. Knutson T. R. Prospects for a prolonged slowdown in global warming in the early 21 st century / T. R. Knutson, R. Zhang, L. W. Horowitz // Nature Communications. 2016. - Vol. 7. - P. 136-176.

22. Kopp G. A new, lower value of total solar irradiance: Evidence and climate significance / G. Kopp, J. L. Lean // Geophysical Research Letters. - 2011. Vol. 38. - L01706.

23. Langenbrunner B. Analyzing ENSO telecomnections in CMIP models as a measure of model fidelity in simulating precipitation / B. Langenbrunner, J. D. Neelin // Journal of Climate. - 2013. - Vol. 26. - P. 4431-4446. 
24. Lewandowsky S. The «pause» in global warming: Turning a routine fluctuation into a problem for science / S. Lewandowsky, J. S. Risbey, N. Oreskes // Bulletin of the American Meteorological Society. - 2016. - Vol. 97. P. 723-733.

25. Palmen E. Atmospheric circulation systems. Their structure and physical interpretation / E. Palmen, C. W. Newton. - New York; London : Academic press, 1969. -615 p.

26. Schurer A. P. Small influence of solar variability on climate over the past millennium / A. P. Schurer, S. F. B. Tett, G. C. Hegerl // Nature Geoscience. - 2014. Vol. 7. - P. 104-108.

27. Sneyers R. On the statistical analysis of series of observations / R. Sneyers // Technical note. - 1990. - № 143. - P. 192.

Чередниченко Александр Владимирович доктор географических наук, доцент, главный научный сотрудник НИИ проблем биологии биотехнологии Казахского Национального университета им. аль-Фараби, г. Алматы, Республика Казахстан, т. +77771625174, E-mail: geliograf@mail.ru

Чередниченко Алексей Владимирович кандидат географических наук, старший научный сотрудник НИИ проблем биологии и биотехнологии Казахского Национального университета им. аль-Фараби, г. Алматы, Республика Казахстан, т. +77772164945, E-mail: aleksey3969@mail.ru

Чередниченко Владимир Сергеевич

доктор географических наук, профессор кафедры гидрологии и метеорологии Казахского Национального Университета им. аль-Фараби, академик международной высшей школы, руководитель проекта, НИИ проблем биологии и биотехнологии Казахского Национального университета им. аль-Фараби, т. +77773551262, E-mail: geliograph@mail.ru
28. Stevenson S. L. Significant changes to ENSO strength and impacts in the twenty-first century: Results from CMIP52012 / S. L. Stevenson // Geophysical Research Letters. - 2012. - Vol. 39. - L17703.

29. Testing for the possible influence of unknown climate forcings upon global temperature increases from 1950 to 2000 / B. T. Anderson [et al.] // Journal of Climate. 2012. - Vol. 25. - P. 7163-7172.

30. The Northern Hemisphere extra tropical atmospheric circulation response to ENSO: How well do we know it and how do we evaluate models accordingly? / C. Deser[et al.] // Journal of Climate. - 2017. - Vol. 30. - P. 5059-5082.

31. Trenberth K. E. Has there been a hiatus? / K. E. Trenberth // Science. - 2015. - Vol. 349. - P. 691-692.

32. Uncertainties in precipitation and their impacts on runoff estimates / B. M. Fekete [et al.] // Journal of Climate. - 2004. - Vol. 1. - P. 293-304.

Cherednichenko Alexander Vladimirovich

Doctor of Geographical Sciences, Associate Professor, Chief researcher of the Institute of biology and biotechnology problems of the Kazakh National University named after al-Farabi, Almaty, Republic of Kazakhstan, tel. +77771625174, E-mail: geliograf@ mail.ru

Cherednichenko Aleksey Vladimirovich

Candidate of Geographical Sciences, Senior scientific researcher of the Institute of biology and biotechnology problems of the Kazakh National University named after al-Farabi, Almaty, Republic of Kazakhstan, tel. +77772164945, E-mail: aleksey3969@mail.ru

Cherednichenko Vladimir Sergeyevich

Doctor of Geographical Sciences, Professor of the Department of hydrology and meteorology of the Kazakh National University named after al-Farabi, Academician of the international higher academician of the international higher school, Project Manager, Institute of biology and biotechnology problems of the Kazakh National University named after al-Farabi, Almaty, Republic of Kazakhstan, tel. +77773551262, E-mail: geliograph@ mail.ru 